\title{
Trends in Stereoselectivity and Regioselectivity for Trimethylsilyl Trifluoromethanesulfonate Addition to Alkynes
}

\author{
John Rivers ${ }^{1}$
}

\section{Abstract}

The trends in stereoselectivity and regioselectivity have been characterised for the reactions of trimethylsilyltrifluoromethanesulfonate (TMS triflate, or TMSOTf) with alkyne substrates. A variety of alkynes were reacted with TMS triflate, yielding the corresponding enol sulfonates, often with high levels of regio- and stereoselectivity.

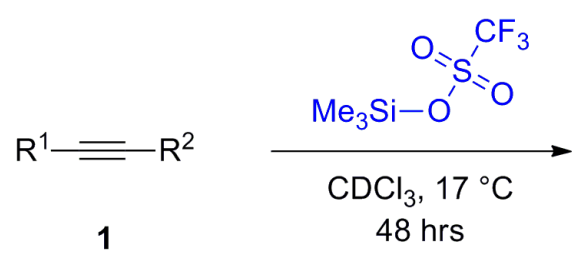

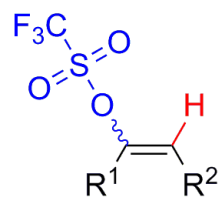

2<smiles>[R]/C=C(/[R])OS(=O)(=O)C(F)(F)F</smiles>

3

\section{Introduction}

Enol triflates are useful functional groups employed in cuprate and palladiumbased coupling reactions. In these reactions, they serve the purpose of halogens, allowing formation of carbon-carbon bonds. They are particularly useful due to their labile nature; studies suggest that triflate is $\sim 10^{\wedge} 6$ times more labile than comparable leaving groups such as mesylates or tosylates.

Although enol triflates have been previously synthesised by trapping enol tautomers of ketone substrates, this technique lacks significant stereoselective control. In previous work, Stang and co-workers have found that synthesis of enol triflates may be achieved by the addition of triflic acid to vicinal and symmetrical alkynes. The acidic nature of these syntheses however, resulted in low yields $(\sim 65 \%)$ due to observed acid-catalysed polymerisation, as well as isomerisation between regio- and stereoisomers. 
Studies into the alternative reaction of trimethylsilyl triflate with symmetrical alkynes by Norris have demonstrated that the addition of triflate occurs with high levels of stereoselectivity.

Herein, the trends in stereoselective and regioselective control with respect to unsymmetrical alkynes are reported, with a view to further optimising this mild generation of enol triflates.

\section{Results}

Our investigation sought to assess the effect different substituents have on both the stereoselectivity and regioselectivity of the formation of enol triflates from alkynes with TMSOTf. The results of these reactions are summarised in Table 1.

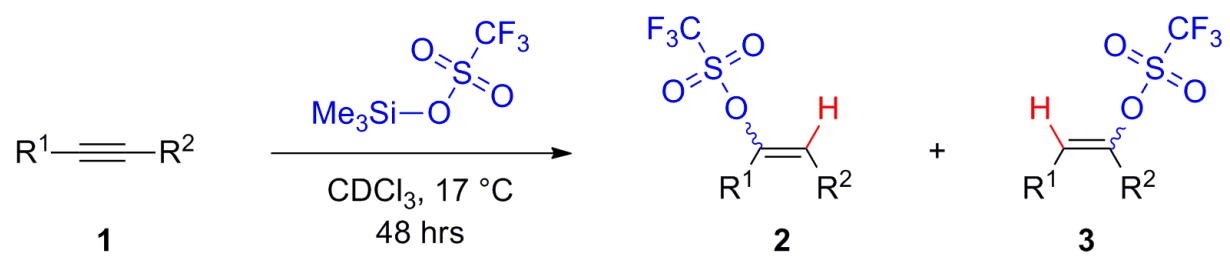

Scheme 1. General scheme for addition of TMSOTf

\begin{tabular}{|c|c|c|c|c|c|}
\hline Entry & $\mathrm{R}_{1}$ & $\mathrm{R}_{2}$ & $\begin{array}{l}\text { Regioisomers } \\
(2: 3)\end{array}$ & $\begin{array}{l}\text { Stereoisomers } \\
(E: Z)\end{array}$ & Combined yield \\
\hline a & $n-\operatorname{Pr}$ & $n-\operatorname{Pr}$ & - & $75: 25$ & $99 \%^{a}$ \\
\hline $\mathrm{b}$ & $n-\operatorname{Pr}$ & $\mathrm{Me}$ & $50: 50^{a}$ & $85: 15^{a}$ & $60 \%^{\mathrm{a}}, 58 \%^{\mathrm{b}}$ \\
\hline c & TMS & $\mathrm{Me}$ & - & - & $0 \%{ }^{a}$ \\
\hline d & $\mathrm{Ph}$ & Et & $100: 0^{c}$ & $40: 60^{d}$ & $73 \%^{a}$ \\
\hline e & $n$-octyl & $\mathrm{H}$ & $100: 0^{a}$ & - & $99 \%^{\mathrm{b}}$ \\
\hline
\end{tabular}

a: Determined by ${ }^{1} \mathrm{H}$ NMR analysis

b: Yield based on isolated product

c: Yield based on isolated 1-phenylbutan-1-one.

$\mathrm{d}$ : Approximate ratio due to an overlap of peaks in the ${ }^{1} \mathrm{H}$ NMR spectrum

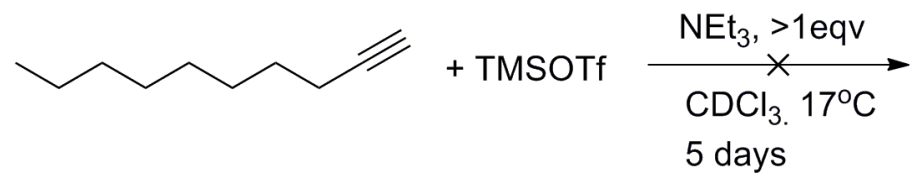

Scheme 2. Attempted reaction of dec-1-yne with TMSOTf in the presence of triethylamine

Treatment of the symmetrically substituted alkyne 4-octyne with TMSOTf (a) resulted in good levels of stereoselectivity 75:25, favouring the $E$ isomer, and 
excellent conversion (99\%) to the enol triflate product as judged by ${ }^{1} \mathrm{H}$ NMR analysis. Reaction of the unsymmetrical alkyne 2-hexyne, (b) which contains an $n$-propyl and a methyl substituent, under the optimal conditions afforded the product in good yields $(58 \%)$. Although a statistical mixture of regioisomers was observed, these product were obtained with high levels of stereoselectivity (85:15), favouring the $E$ isomer.

When a trimethylsilyl substituted alkyne was subjected to the reaction conditions (c), only the starting material was observed, even after 5 days.

Reaction of a phenyl substituted alkyne (d) afforded a single regioisomer, which corresponded to the enol triflate formed at the benzylic position, as judged by ${ }^{1} \mathrm{H}$ NMR of the crude reaction mixture. This reaction proceeded with little stereoselectivity, observed in an $E: Z$ ratio of 40:60.

Attempts to isolate the enol triflate product by flash chromatography, using silica gel as the stationary phase, resulted in hydrolysis of the product to the corresponding ketone producing 1-phenylbutan-1-one in $73 \%$ yield, based on isolated product. The structure of this ketone was confirmed via comparison of the NMR spectrum with that previously reported.

\section{Overall Interpretation of the Results}

\section{Regioselectivity}

With respect to regioselectivity, the reaction of TMSOTf with alkynes appears to follow Markovnikov addition in that the carbon atom of the alkyne most able to stabilise a carbocation is attacked by the triflate anion. For example, when a terminal alkyne was used, a secondary enol triflate was observed (entry e), which agrees with the formation of a secondary carbocation over a primary. Furthermore, when a phenyl substituted alkyne was used, the enol triflate generated corresponded to the trapping of a benzylic carbocation (entry d).

The results of entry c also point to the regioselective dependence on the distribution of electronic density along the alkyne bond. No reaction was observed in entry c.

Considering entry c, we observe that the alkyne bond of the substrate should be polarised, with more negative character towards the silyl group, ${ }^{7}$ and proton addition should occur at the a- carbon with respect to the silyl substituent. This result is plausible evidence that the proton source is more sterically hindered than triflic acid. 
Further examples, that contain more hindered alkyl groups such as t-butyl, would be required in order to prove this hypothesis and also to understand the deactivation effect of the TMS group.

Evidence that the proton source is a Brønsted acid was demonstrated by the lack of reaction observed in the presence of triethylamine (Scheme 2), which was present in a 1:1 molar ratio with respect to the starting material.

The TMSOTf reagent could simply be a reagent that slowly releases triflic acid in small quantities, due to the presence of residual water and the reactivity observed would be similar to acid addition to alkynes. The proton-source may be the hydrolysis by-products of TMSOTf, such as $\mathrm{TMSOH}_{2}^{+}$or (TMS) $)_{2} \mathrm{OH}^{+}$.

This proposition would be supported by the observed Markovnikov regioselectivity, the total lack of reactivity in the presence of base and the long reaction times.

\section{Stereoselectivity}

With regard to stereoselectivity, there are two observed modes of addition, apparently dictated by the identity of the substrate. In the case of triflate addition to internal, aliphatic alkynes, the reactions studied display preference for $E$ isomers, with syn addition of triflate anion and proton (entries a and b). In contrast, addition to alkynes bearing an aromatic group (entry d) resulted in an $E: Z$ ratio of 40:60, with only slight preference for the $Z$ isomer.

It is possible that the presence of a charge stabilizing aromatic substituent allows for the formation of a cationic intermediate, resulting in the loss of specificity, although little evidence currently exists to support this.

The mode of addition of TMSOTf to terminal alkynes has not been examined and further insights may be gained from reaction of TMSOTf with deuterated substrates such as $d$-1-decyne, as well as aromatic substrates such as $d$ phenylacetylene.

\section{Proposed Mechanism}

In proposing a reaction mechanism, the points to be considered are that the reaction is halted in the presence of a base, favours syn addition for aliphatic substrates and has reduced selectivity in the case of aromatic ones. 
Previous work by Summerville and Schleyer ${ }^{10}$ has demonstrated that addition of triflic acid to 1-hexyne also proceeds with complete syn-selectivity. The observed syn-selectivity is not unique to TMSOTf and the arguments justifying syn-selectivity in TMSOTf addition must also hold for the triflic acid addition.

The most plausible explanation involves a cationic intermediate. Such a pathway would be stabilised by resonance in the case of aromatic substrates, as depicted in Scheme 3. In the case of aliphatic substrates, the triflate addition would occur on the least hindered face of the intermediate, consistent with syn-selectivity.

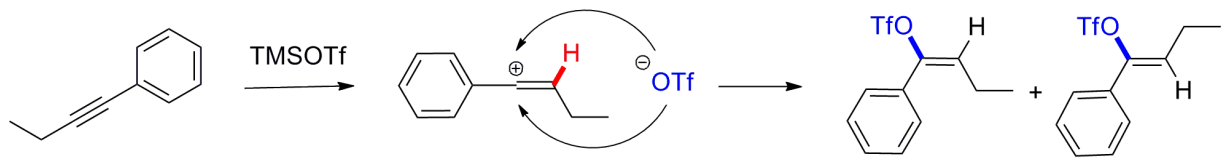

\section{Scheme 3. Proposed cationic-intermediate reaction pathway}

Syn-selectivity of triflate addition to carbocations due to steric hindrance has been previously observed. In a reaction by Chavre and co-workers, ${ }^{11}$ the carbocation obtained was trapped by a triflate anion, giving the enol triflate product depicted in Figure 1. The addition of the triflate ion is dictated by steric hindrance, supporting the syn-selectivity observed in this study.

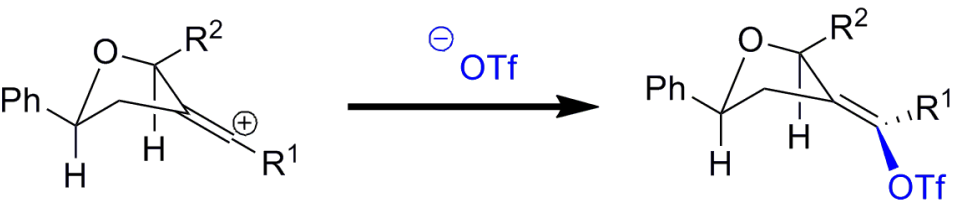

Figure 1. Trapping of sterically less-hindered enol triflate by Chavre et al. $\mathbf{R}^{2}=\mathrm{CHO}$

With respect to entry $d$, if it is true that a cationic intermediate intervenes in aromatically-substituted substrates, solvent choice may be expected to influence stereoselectivity.

Further understanding of this reaction will require greater knowledge and understanding of the proton source. Use of deuterated TMS in studies would be able to conclusively verify TMS as the proton source.

Experiments could also be undertaken to determine the fate of the deprotonated TMS group. It has been hypothesised that 1,1-dimethylsilene is formed, a theory that could be verified by addition of 1,3-cyclohexadiene to the reaction mixture, trapping any silene by-product via a Diels-Alder reaction. ${ }^{12}$ The work of Trommer and co-workers has also noted that the silene can be trapped via a $[2+2]$ cycloaddition with formaldehyde. 
Previous studies by Norris have also found that stereoselectivity may be modified by the use of $t$-butyldiphenylsilyl (TBDPS) instead of TMS as the silyl substituent for the triflate, suggesting crucial participation of the silyl group in the transition state. It is likely further studies reacting TBDPSOTf with unsymmetrical substrates will provide further insight into the mechanism of TMSOTf addition to alkynes.

\section{Yield}

Yields for TMSOTf addition are generally reasonable, with $>80 \%$ conversion to product for TMSOTf addition to aliphatic internal alkynes observed here and in previous studies. This is a significant improvement on previous techniques for enol triflate formation employing triflic acid, in which significant proportions (30-40\%) of the starting material were found to polymerise into a dark, reddish-purple mass. A similar polymeric mass is also present in our reactions, although to a diminished extent. The tendency of the enol triflates to regio- and stereoisomerise under acidic conditions has also been observed by Stang and co-workers. This isomerisation could explain the incomplete selectivity, which would favour the formation of the thermodynamically more stable isomer(s).<smiles>[R]C=C([R])OS(=O)(O)(OC([R])=C[R])OS(=O)(O)(O)C(F)(F)F</smiles>

\section{Scheme 4. Acid-catalysed stereo-isomerisation mechanism}

Considering the previous success of triflate reactions with oct-4-yne, it is particularly surprising that reaction b should yield only $58 \%$. This is assumed to be an isolated incident.

It is interesting to note the instability of enol triflates $2-Z \mathrm{~d}$ and $2-E \mathrm{~d}$ towards silica gel. This is attributed to silica-mediated hydrolysis proceeding via a known mechanism. This degradation was not observed during isolation of other enol triflates. The presence of the phenyl substituent may be activating with regards to hydrolysis, suggesting other aromatically- $\beta$-substituted enol triflates are also prone to silica hydrolysis; this remains to be confirmed. Should the use of aromatically- $\beta$-substituted enol sulfonates in further synthesis be desired, another means of isolation must be employed, or further reactions attempted in situ. 


\section{Conclusions}

The regio- and stereo-selective properties of TMS triflate regarding addition to unsymmetrical alkynes have been established, suggesting complete Markovnikov regioselectivity in terminal and aromatically-substituted alkynes. TMS triflate appears to promote selective addition to internal aliphatic alkynes, with up to $85 \%$ selectivity for the $E$ isomer. The stereoselectivity of addition to aromatically-substituted alkynes, under current conditions, appears to be substrate-controlled.

Further studies in this methodology should be directed towards greater mechanistic understanding of TMS triflate addition to alkynes. Deuterated substrates, as well as deuterated TMS triflate should yield further insights into the reaction mechanism(s), allowing greater control over triflic acid addition. The proposed intermediary effect of water should also be investigated; both reactions carried out in dry solvent and those with added water are of interest.

This mild method for the formation of enol triflates has considerable potential for application. The use of alternative solvents, with aromatic alkynes in particular, should lead to greater control over stereoselectivity.

\section{Experimental}

Reactions were carried out in $\mathrm{CDCl}_{3}$ solvent at $17^{\circ} \mathrm{C}$, with deuterated chloroform employed in order to eliminate possible acidic conditions known to catalyse $E / Z$ isomerisation. Regio- and stereoselectivity were determined, as described in the entries below, via ${ }^{1} \mathrm{H}$ NMR analysis. A nitrogen atmosphere was employed to avoid exposure to excess moisture.

\section{General Procedure A for the Formation of Enol Triflates}

A magnetically-stirred solution of alkyne (1 eq) in $\mathrm{CDCl}_{3}(0.3 \mathrm{M}$ with respect to the alkyne) was treated with TMSOTf (1.3 eq). After the specified time (48hrs) a $1 \mathrm{ml}$ aliquot was taken and analysed by ${ }^{1} \mathrm{H} \mathrm{NMR}$. When the reaction was deemed complete, the reaction was subjected directly to flash chromatography (silica, $100 \%$ hexane eluent). In some cases isolation was not pursued due to time constraints; nevertheless it has been noted by Norris that aliphatic enol triflates can be isolated via flash chromatography. 


\section{General Procedure B for Determination of Regio- and Stereoisomers via ${ }^{1} \mathrm{H}$ NMR}

Regioisomers were determined on the basis of signal-splitting. For the ${ }^{1} \mathrm{H}$ NMR spectrum of $2 \mathrm{~b}$ and $3 \mathrm{~b}$ (i.e. (2E/Z)-hex-2-en-3-yl trifluoromethanesulfonate + (2E/Z)-hex-2-en-2yl trifluoromethanesulfonate) example below, regioisomers were distinguished due to their different vinylic proton splitting patterns, with the hex-2-en-2-yl isomers expected to give a triplet, and a quartet expected of hex-2-en-3-yl isomers.

Stereoisomers were distinguished based on chemical shift of the vinylic proton signals in the region 4-6 ppm. The downfield signal in each case of regioisomers was attributed to the $Z$ isomer, due to the greater negative-induction known to be exerted by trans-substituents. In the example below ((4E/Z)-oct-4-en-4-yl trifluoromethanesulfonate), the $Z$-isomer vinylic peak occurs at $5.45 \mathrm{ppm}$ whilst the $E$-isomer (with vinylic proton cis to triflate) has a peak at $5.20 \mathrm{ppm}$.

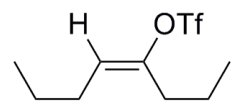

2-E a

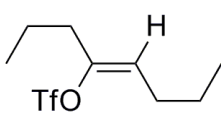

2-Z a

(4E/Z)-oct-4-en-4-yl trifluoromethanesulfonate

General procedure A: Oct-4-yne $(0.07 \mathrm{ml}, 0.48 \mathrm{mmol})$ was employed. The product was not isolated from the work-up.

${ }^{1} \mathrm{HNMR}\left(300 \mathrm{MHz}, \mathrm{CDCl}_{3}\right)$ : $\delta \mathrm{ppm}$ 0.91-0.97 (6H, m, $\left.\mathrm{CH}_{3}\right), 1.39-1.47(2 \mathrm{H}, \mathrm{m}, J=$ $\left.\left.7.4 \mathrm{~Hz}, \mathrm{CHCH}_{2} \underline{\mathrm{C}}_{2}\right), 1.51-1.58(2 \mathrm{H}, \mathrm{m}, J=7.5 \mathrm{~Hz}), \mathrm{C}(\mathrm{OTf}) \mathrm{CH}_{2} \mathrm{CH}_{2} \mathrm{CH}_{3}\right), 2.11-2.19$ $\left(2 \mathrm{H}, \mathrm{q}, J=7.8 \mathrm{~Hz}, \mathrm{CHC}_{2}\right), 2.27-2.32\left(2 \mathrm{H}, \mathrm{t}, J=7.7 \mathrm{~Hz}, \mathrm{C}(\mathrm{OTf}) \mathrm{CH}_{2}\right), 5.19(0.75 \mathrm{H}$, $\mathrm{t}, J=7.4 \mathrm{~Hz}, \mathrm{C}(\mathrm{OTf})=\mathrm{C} \underline{\mathrm{H}}(E)), 5.46(0.25 \mathrm{H}, \mathrm{t}, J=7.4 \mathrm{~Hz}, \mathrm{C}(\mathrm{OTf})=\mathrm{C} \underline{\mathrm{H}}(Z))$.<smiles>CC=C(O)CCC</smiles>

2-E b<smiles>CC=C(O)CCC</smiles>

$2-Z$ b<smiles>CCCC=C(C)[OH2+]</smiles>

3-E b<smiles>CCCC=C(C)[OH2+]</smiles>

$3-Z b$

(2E/Z)-hex-2-en-3-yl trifluoromethanesulfonate $+(2 E / Z)-h e x-2-e n-2 y l$ trifluoromethanesulfonate

General procedure A: Hex-2-yne $(0.214 \mathrm{ml}, 1.9 \mathrm{mmol})$ was employed. Approximately $58 \%$ conversion of starting material was achieved. The product mixture was separated from the work-up. No attempt was made to isolate the isomers.<smiles>CC/C=C(\[O])c1ccccc1</smiles>

2-E d<smiles>CC/C=C(\[O])c1ccccc1</smiles>

$2-Z d$ 
General procedure A: 1-phenylbut-1-yne $(0.27 \mathrm{ml}, 1.9 \mathrm{mmol})$ was employed. Approximately $73 \%$ conversion to product was achieved. In a modification to the general chromatography procedure, hexane eluent was used to remove the starting material before use of ethyl acetate to elute the product. It was found, upon NMR analysis of the product, that hydrolysis had occurred during elution, with the isolated product ${ }^{1} \mathrm{H}$ NMR identical to that of 1-phenylbutan-1-one.

${ }^{1}$ H NMR (300MHz, $\left.\mathrm{CDCl}_{3}\right)$ : Vinylic peaks: $5.74(0.4 \mathrm{H}, \mathrm{t}, J=6 \mathrm{~Hz}, \mathrm{C}(\mathrm{OTf})=\mathrm{C} \underline{\mathrm{H}}$ (E), $5.77(0.6 \mathrm{H}, \mathrm{t}, J=9 \mathrm{~Hz}, \mathrm{C}(\mathrm{OTf})=\underline{\mathrm{CH}}(Z)$.

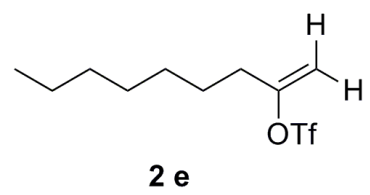

\section{dec-1-en-2-yl trifluoromethanesulfonate}

General procedure A: dec-1-yne $(0.34 \mathrm{ml}, 1.9 \mathrm{mmol})$ was employed.

In addition to General procedure $\mathrm{B},{ }^{13} \mathrm{C}$ NMR and IR techniques were used to characterise the molecule.

${ }^{1} \mathrm{HNMR}\left(300 \mathrm{MHz}, \mathrm{CDCl}_{3}\right): \delta 0.829\left(3 \mathrm{H}, \mathrm{t}, J=5.5 \mathrm{~Hz}, \mathrm{CH}_{3}\right), 1.251\left(10 \mathrm{H}, \mathrm{m},\left(\mathrm{C}_{2}\right)_{5}\right)$, $1.48\left(2 \mathrm{H}, \mathrm{m}, J=4.0 \mathrm{~Hz}, \mathrm{C}(\mathrm{OTf}) \mathrm{CH}_{2} \mathrm{C} \underline{\mathrm{H}} 2\right), 2.274\left(2 \mathrm{H}, \mathrm{t}, J=5.70 \mathrm{~Hz}, \mathrm{C}(\mathrm{OTf}) \mathrm{C}_{2}\right)$, $4.864(1 \mathrm{H}, \mathrm{dt}, J=2.7 \mathrm{~Hz}, \mathrm{C}(\mathrm{OTf})=\mathrm{C} \underline{\mathrm{H}}(E), 5.025(1 \mathrm{H}, \mathrm{d}, J=2.7 \mathrm{~Hz}, \mathrm{C}(\mathrm{OTf})=\mathrm{C} \underline{\mathrm{H}}$ (Z). ${ }^{13} \mathrm{C}$ NMR $\left(100 \mathrm{MHz}, \mathrm{CDCl}_{3}\right): \delta 12.156,20.75,24.103,26.758,27.238,27.285$, 29.910, 31.969, 102.055, 155.262 IR (neat oil film): $v \mathrm{~cm}^{-1} 2931-2859$ (m, CH stretching), 1671 (m, C=C stretch), 1458, 1419 ( $\mathrm{m}, \mathrm{CH}_{3}$ and $\mathrm{CH}_{2}$ deformations), 1210 (s, S=O stretch), 1141 (s, CF stretch).

\section{References}

Scott, W. J., McMurry, J. Acc. Chem. Res. 1968, 21, 47.

Fleming, I., Ramaro, C. Org. Biomol. Chem. 2004, 2, 1510.

Summerville, R., Senkler, C., Schleyer, P., Stang, P., et. al. J. Amer. Chem. Soc. 1973, 96, 1100 .

Norris, M., Sharp, P. P., Banwell, M.; Australian National University: Canberra, 2009, unpublished manuscript.

Pan, P., et. al. J. Org. Chem. 2009, 74, 7364.

Pouchert, C. J. The Aldrich library of FT-IR spectra; Aldrich Chemical Company: Milwaukee, Wis. USA, 1989.

Colvin, E. W. SILICON IN ORGANIC SYNTHESIS; Butterworths: Boston, 1981. 
The ANU Undergraduate Research Journal

Kresge, A., J. Chiang, Y. J. Amer. Chem. Soc. 1962, 84, 3976.

Noyce, D., Schiavelli, M. J. Amer. Chem. Soc. 1968, 90, 1023.

Summerville, R. H.; Schleyer, P. V. R. Journal of the American Chemical Society 1972, 94, 3629.

Chavre, S. N.; Choo, H.; Cha, J. H.; Pae, A. N.; Choi, K. I.; Cho, Y. S. Organic Letters 2006, 8, 3617.

Auner, N., Seidenschwarz, C., Sewald, N. Organometallics 1992, 11, 1137.

Trommer, M., Sander, W., Patyk, A. Angew. Chem. Int. Ed. 1995, 34, 929.

Trommer, M., Sander, W., Patyk, A. J. Amer. Chem. Soc. 1993, 115, 775.

Stang, P. J., Summerville, R. J. Amer. Chem. Soc. 1969, 91, 4600.

Goundry, W. Synlett 2003, 12, 1940. 